George Beilby's statement that the point of view of the engineer is not so far removed from that of the ordinary intelligent person that the latter cannot grasp, in a general way, his aims and objects; but the thoughts and aims of the chemist are for the most part quite inscrutable to the vast majority of his fellow-men. Since the chemist's views are so much further removed from everyday notions and conceptions than are those of the engineer, it is wiser first to imbue the mind of the student thoroughly with the more difficult, because less ordinary, point of view.

On the other hand, many of the speakers seemed to advocate that chemists should be trained as chemical engineers-that is, primarily to design and control chemical plant; and that the factor of cost in relation to chemical processes should not be overlooked. From the point of view of the chemical manufacturer, it was urged that the main requirement of the industry was men fully equipped with a real knowledge of chemistry: the individual with mechanical aptitude would without difficulty be able to learn enough to think as an engineer, and appreciate engineering problems.

In addition to the scheme outlined by Prof. Donnan for the training of the would-be works chemist in engineering, papers were contributed by $\mathrm{Mr}$. C. H. Darling on the training in physics given at the Finsbury College, and by Mr. J. W. Hinchley on the course at the Imperial College. The former course is designed to make the student acquainted with the type of instrument he will later meet with in works, but it was recognised by Mr. Darling that the young chemist who is to be of the maximum use to his employer must, in addition to the possession of specific knowledge, have his ideas running in the right grooves.

\section{HIGH-SPEED TELEGRAPHY.}

THE report of the committee appointed by the Postmaster-General in December, 1913 , to consider the question of high-speed telegraphy has now been issued in the form of a White Paper (Cd. 84I3, price $3 d$.). Unfortunately the work of the committec was interfered with by the outbreak of war in August, I9I4, which cut short a series of tests designed to show the best results which various competing systems could produce under identical conditions. In the absence of comparative statistics the complete examination of all the claims of rival inventions is impossible, but as such minute statistical comparisons would be mainly valuable in connection with further investigation, the considerations on which the committee's recommendations have been framed should suffice for the present.

The question before the committee resolved itself into a rivalry between automatic high-speed systems on one hand, and the multiplex on the other, though the inventions of $\mathrm{Mr}$. Creed and the advent of various keyboard perforators affected the situation of the former. Automatic high-speed svstems were fully reviewed, but the conclusion arrived at by the committee is that for ordinary commercial telegraph work between the main centres of the British Post Office service the inventions based on the multiplex method are superior, as they conduce to economy in staff, are subject to fewer serious stoppages and delays than automatic systems, and necessitate less spare plant and less costly maintenance. The fundamental principles of nearly all multiplex instruments are based on the Baudot system, invented more than thirty years ago. Ten years later it assumed, in the hands of the original inventor, practically its present form. Although some of its main principles had been anticipated by earlier inventors, Baudot was the first who combined them into a system of practical utility, and the production of the system may be regarded as marking an epoch in the history of telegraphy. The leading features of the Baudot system are: (I) its method of obtaining synchronism; (2) its direct transmission from keyboard to line; (3) its cadence and speed; (4) its direct printing on slip.

Of the multiplex systems at present available, the Western Electric is said to have given the best results, and the committee recommends that a number of quadruple duplex installations of this apparatus be ordered. Seven or eight sets should suffice, as al. though present conditions favour the rapid application of systems with the greatest output, it is desirable to avoid too great a dislocation of working, and to allow time, so far as possible, for other makers to demonstrate their capabilities. Pagre- or columnprinting is preferable to tape-printing on the busiest routes, and the Western Electric Company's pageprinting on a continuous roll of paper, cut off after each message, is quite satisfactory. The com. mittee does not consider it desirable that either page- or column-printing should be adopted throughout the service to the exclusion of tape-printing, while the Creed receiving apparatus is recommended for use in the Post Officc news service. The application of printing methods to the less im. portant circuits should be kept steadily in view, and early trials of the one-way and two-way installations of the Western Electric, and of the light line printer of the Automatic Telephone Manufacturing Company, are recommended. The committee was impressed with the possibility of two-way working with one operator at each end, both to signal their messages simultaneously to the other end, and then both to gum the tape. An hourly load can be carried in this way equivalent to the average Morse load with two operators at each end, and having the additional advantage of printing the telegrams. The committee predicts that the introduction of multiplex methods for news work will call for serious consideration in the near future, and it urges that the application of these systems, to give simultaneous communication on one wire between each one of three or possibly more offices, should be kept in view as multiplex methods are extended.

\section{HEREDITY AND DISEASE.}

I $\mathrm{N}$ the lately issued Bulletins Nos. 16 and $I 7$ of the Eugenics Record Office (Cold Spring Harbour, New York) Prof. C. B. Davenport and Dr. Elizabeth B. Muncey discuss "Huntington's Chorea in relation to Heredity and Eugenics" and "The Hereditary Factor in Pellagra." Nearly a thousand cases of the chorea "can be traced back to some half-dozen individuals who migrated to America during the seventeenth century." The disease manifests itself in various sets of symptorns-nervous tremors, dementia, etc., -most of which act as dominants. Though the hereditary nature of the disease has been recognised for generations, "there is no clear evidence that persons belonging to the choreic lines voluntarily abstain to any marked degree from, or are selected against, in marriage." With regard to pellagra, there appears to be a distinct hereditary predisposition to infection. nearly half the children of a pair of susceptible parents are themselves susceptible.

The long-disputed question of the influence of poison on germ-cells has received another contribution in Dr. Raymond Pearl's paper on the effect of continued 